\title{
Standardize Transcatheter Aortic Valve Implantation with CoreValve self expandable prosthesis and post procedurals management
}

\author{
Gian Paolo Ussia, Valeria Cammalleri, Francesco Romeo \\ Università degli Studi di Roma „Tor Vergata”, Italy
}

T ranscatheter aortic valve implantation (TAVI) is a therapeutic alternative to surgical aortic valve replacement (SAVR) or palliative medical therapy for patients with symptomatic severe aortic valve stenosis (AVS) $)^{1-5}$. The high surgical risk for a patients with aortic valve stenosis has to be assessed jointly with the cardiac surgeon and the cardiac anaesthesiologist, as indicated in the guidelines for valvular heart disease management issued by the European society of cardiology in $2012^{6}$. Results from registries and trial are favourable with unexpected results of prosthesis performance and survival rate at 3 and 5 years of follow up ${ }^{7-13}$

TAVI carries higher risk of post procedural adverse events than conventional percutaneous cardiovascular interventions, due to the baseline clinical condition of the patients and to the associated comorbidities.

Therefore, careful patient monitoring in a intensive care unit (ICU) during the first 48 hours seems to be extremely important to early detect and manage complications, as well as decrease the rate of adverse events and the length of in-hospital stay.

\section{Preprocedural patient assessment}

Pre-procedure evaluation include transthoracic echocardiography, invasive cardiac evaluation with right and left cardiac catheterization, coronary angiography and cardiac and vascular multislice computed tomography (MSCT). The baseline risk of the patients population is estimated by the logistic EuroScore, EuroScore II and STSPROM score ${ }^{14-18}$. Adjunctive risk criteria, not included in these scores are frailty, porcelain aorta, severe liver disease/cirrhosis, hostile chest, severe right ventricle dysfunction, chest radiation, degenerative neurological disorders, patent internal mammary artery or other critical conduits adherent to the sternum, severe right ventricle dysfunction, or any contraindication to extracorporeal circulation ${ }^{19}$. Transthoracic or transesophageal echocardiography are needed to diagnose the aortic stenosis, assess the left ventricular function, characterize the other valves, and determinate pulmonary pressure. These elements are of paramount importance for planning the procedure and stratify the procedural risks (figure 1). Furthermore MSCT plays a crucial role in the screening of

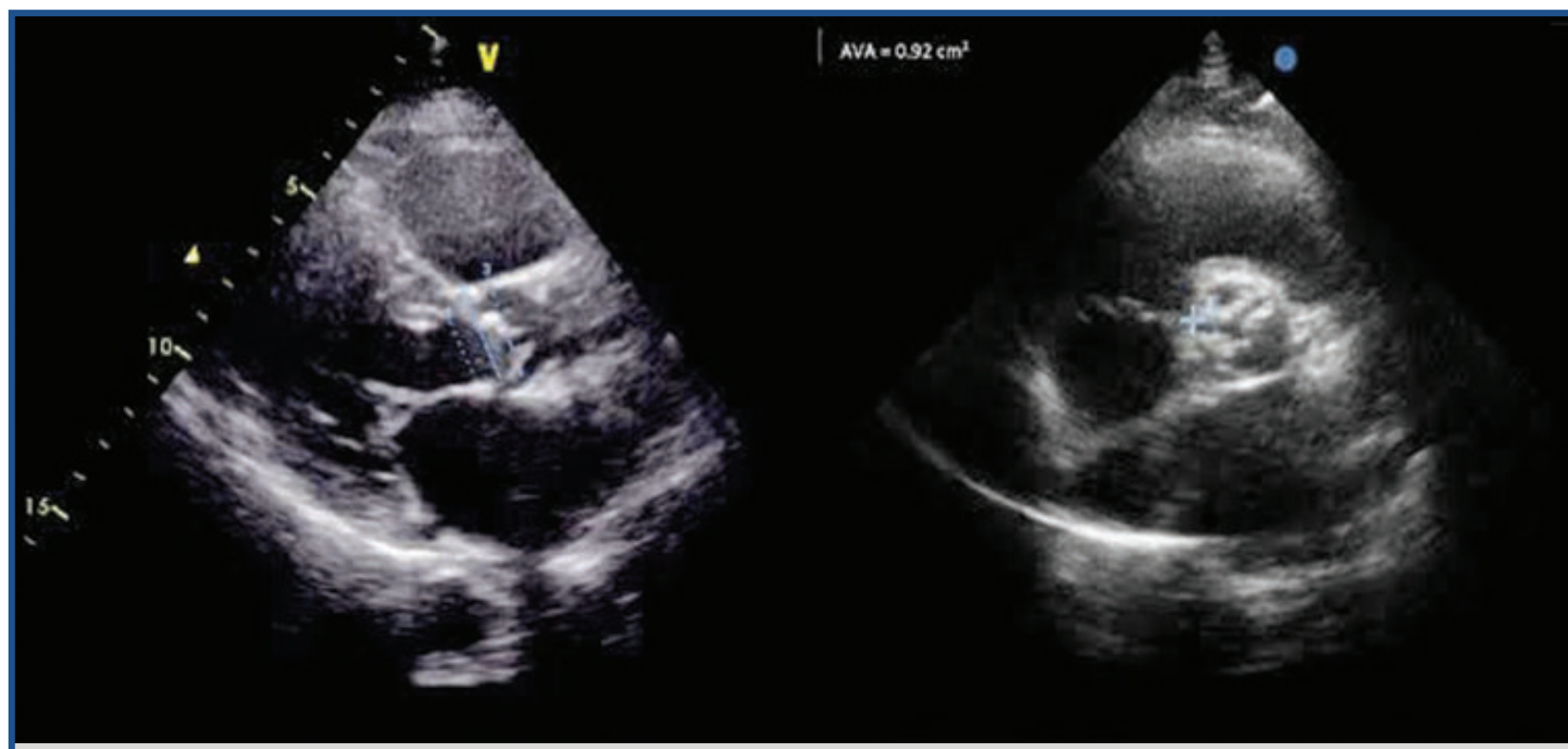

Figure 1. Transthoracic echocardiogram in parasternal long-axis and short-axis view. The aortic valve is examined, with particular attention to the left ventricular outflow tract diameter (1), annulus (2) and sinus of Valsalva width (3). Valvular calcium distribution and planimetric artic valve area (AVA) are also assessed.

Correspondence to Gian Paolo Ussia, MD, Department of Cardiovascular Disease, Tor Vergata University of Rome, Rome, Italy, Viale Oxford, 81; 00133 Rome, e-mail: Gian.Paolo.Ussia@uniroma2.it, phone: 00390620904009, fax 00390620904008 


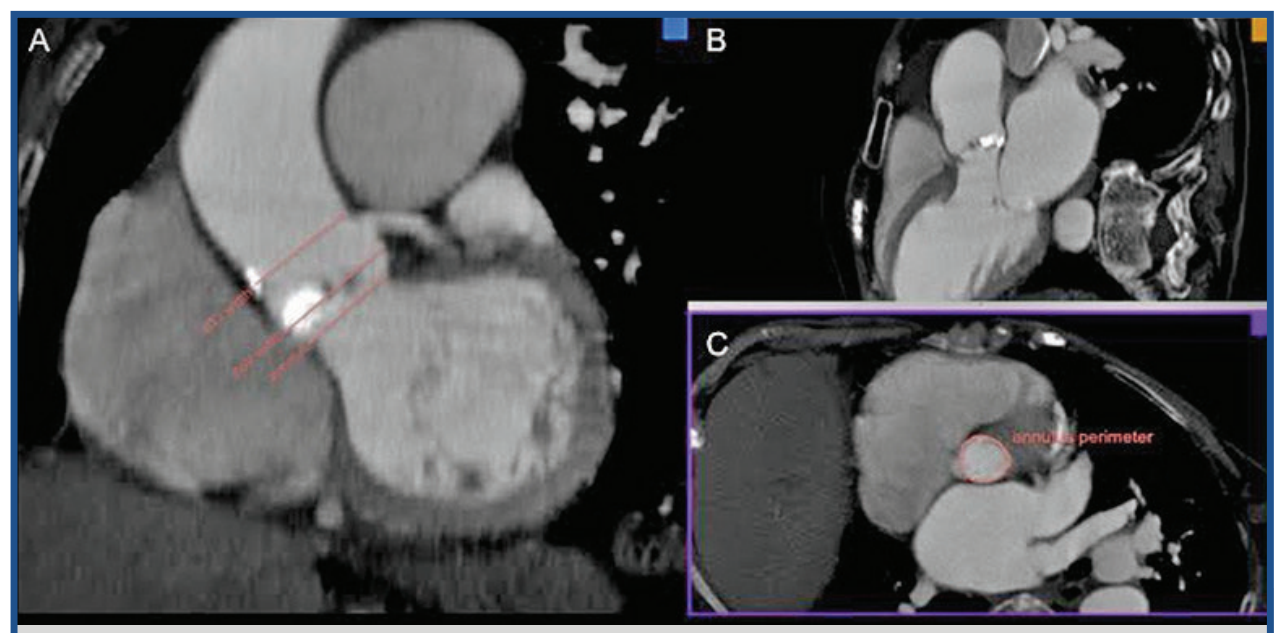

Figure 2. Multiplanar reconstruction of a cardiac MSCT. The three planes are examined. A) Coronal plane the left ventricular outflow tract, aortic annulus, sinus of Valsalva, sinu-tubular junction and coronary take off are measurable; B) sagittal plane, ascending aorta visualization and it helps for optimal orientation of the coronal plane; C) transversal plane, the perimeter of the aortic valve annulus is measured in this view.

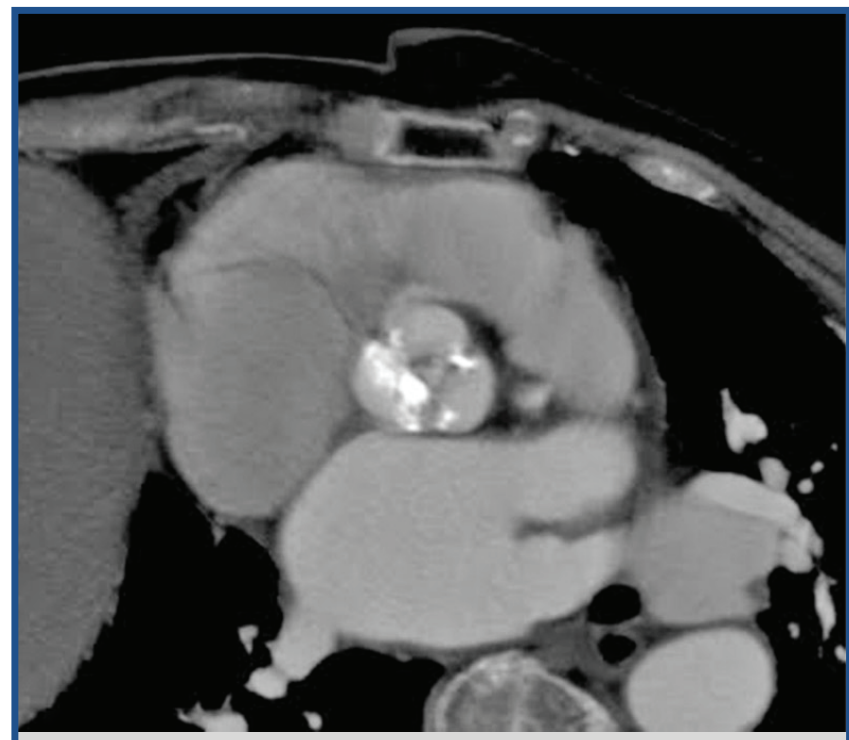

Figure 3. Transversal plane of multiplanar reconstruction of a cardiac MSCT. This projection allow to determinate the anatomy of the cusps, to rule out bicuspid valve and evaluate calcium distribution.

patients candidate to TAVI. It allows careful evaluation of the aortic valve apparatus: aortic valve morphology diameter and perimeter, calcification burden, annulus, left ventricular outflow tract, sinus of Vasalva height and length, coronary ostia take off (Figure 2 and 3 ). This allows a correct sizing and the selection of the better prosthesis. Angio CT-scan of aorto-iliac and femoral arteries is important for choosing the optimal vascular access (figure 4), i.e, femoral route or alternative, such as the trans-axillary/subclavian access, which consisted in a surgical exposure of the proximal part of the transaxillary artery, showing clear advantage in hostile vessel anatomies ${ }^{20-23}$; the trans-apical with surgical exposure of the left ventricular apex using customized introducer, balloon and device; and the last described approach, which is the trans-aortic one, requiring surgical access of the ascend-

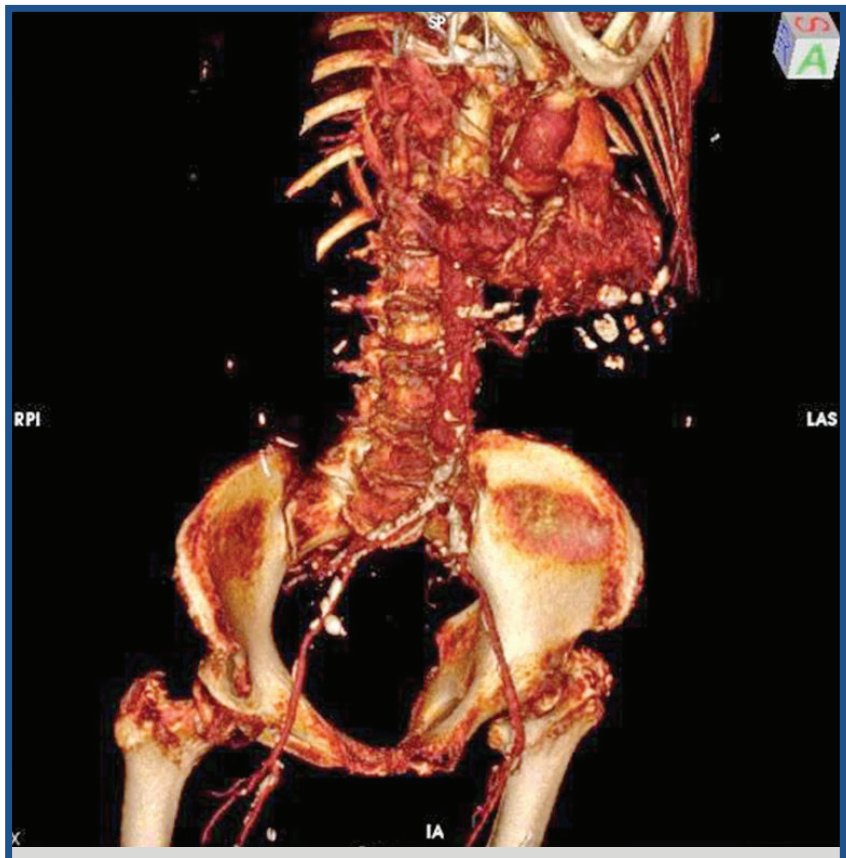

Figure 4. Three dimensional reconstruction of the aorto-ilio-femoral axis; diameter and calcifications can be analyzed using the transverse plane.

ing aorta. All these vascular routes showed to be safe in selected patients, with high procedural success and acceptable complication rate ${ }^{24}$.

Once the patient is judged suitable for TAVI because all the clinical indication requirements (valvulopathy and surgical risk) have been satisfied and the aortic valve anatomy refereed suitable, it is necessary to evaluate the pre procedural clinical condition, ruling out any pulmonary or urine infections and hemocuagulative disorder, and assess lung, renal and hepatic function, in order to be ready to face promptly any complications secondary to comorbidities. A 24 hours ECG Holter monitoring is recommended to detect baseline rhythm disorders. 


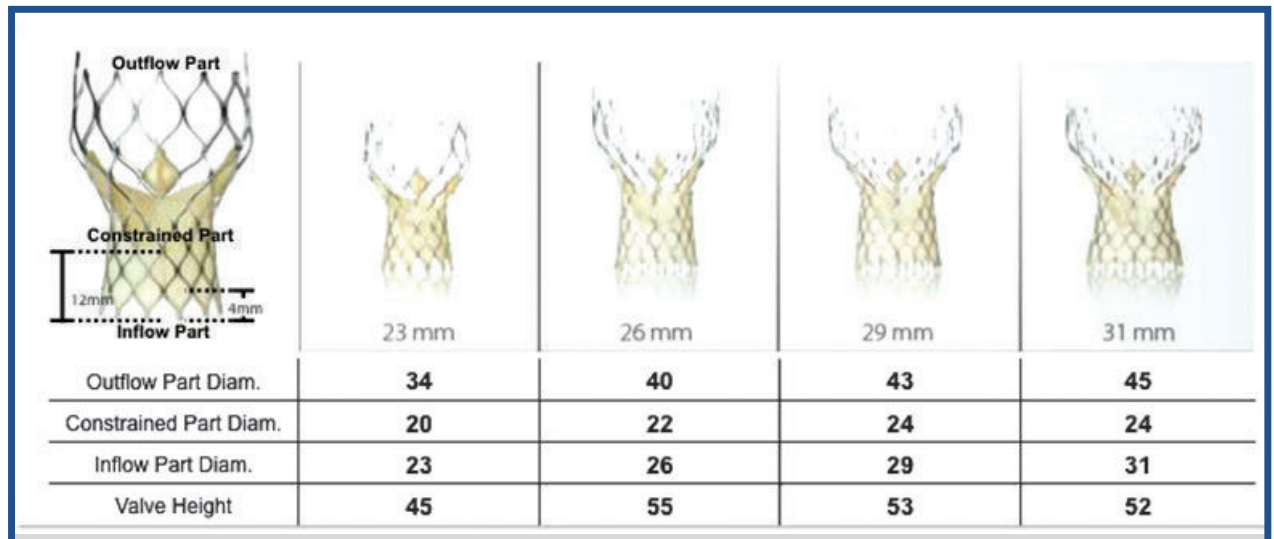

Figure 5. The e CoreValve ${ }^{\circledR}$ family (Medtronic, Minneapolis, MN, USA ). The prosthesis frame consists of three distinct regions: the lower inflow portion that has high radial strength for facilitating device anchoring; the constrained middle portion, which incorporates the valve leaflets and has the smallest diameter to avoid coronary ostial jailing and the outflow portion serving to orient the frame to the direction of blood flow in the ascending aorta .

A standardized pre-medication regimen consists of aspirin $100 \mathrm{mg}$ once daily and loading dose of Clopidogrel $300 \mathrm{mg}$ on the day before the procedure. Prophylactic antibiotic therapy is administered 24 hours before TAVI. Moreover, two units of concentrated red cells are reserved in consideration for the possibility of haemorrhagic complications.

\section{Device and procedure description}

The third generation 18 French CoreValve Revalving ${ }^{\circledR}$ System for TAVI (Medtronic Inc. MN, USA) is a self expandable nitinol frame with a biological valve made of porcine pericardium available in four sizes (figure 5): the $23 \mathrm{~mm}$ CoreValve ${ }^{\circ}$ Evolut $^{\mathrm{TM}}$ prosthesis is indicated for annulus $18-20 \mathrm{~mm}$ and perimeter $56,5-62,8 \mathrm{~mm}$; the $26 \mathrm{~mm}$ prosthesis is indicated for annulus $21-23 \mathrm{~mm}$, perimeter $62,8-72,2 \mathrm{~mm}$; the $29 \mathrm{~mm}$ valve is indicated in annulus $24-27 \mathrm{~mm}$, perimeter $72,2-84,8 \mathrm{~mm}$; the $31 \mathrm{~mm}$ valve is indicated in annulus $27-29 \mathrm{~mm}$ and perimeter $81,6-91,1$ $\mathrm{mm}$. The prosthesis frame is comprised of three distinct regions that interact with the aortic root at different levels (figure 5). The lower inflow portion has high radial strength for facilitating device anchoring. The constrained middle portion incorporates the valve leaflets and has the smallest diameter to avoid coronary ostial jailing. The outflow portion serves to orient the frame to the direction of blood flow in the ascending aorta.

The procedures are performed with surgical back up, under fluoroscopic guidance, and in a standard cardiac catheterization laboratory.

The anaesthesiological management is chosen basing on the patient condition. In our center analgo sedation without endo-tracheal intubation is the preferred approach for the following reasons: more stable hemodynamic of the patient, spontaneous breathing, shorten inICU stay and reduction in post procedural pulmonary disorders. Further extubation time in case of general anaesthesia and traditional endo-tracheal intubation is an unpredictable factor, especially for elderly people who have lung diseases and other severe comorbidities. Gen- eral anaesthesia is the preferential way during transaortic or transapical access, or other accesses when transesophageal ehcoacardiographic monitoring is required. For adequate patient monitoring during the intervention it is always recommended a central venous catheter (CVC) placed in the right jugular vein or left subclavian vein in all patients for drug delivery, fluid administration and monitoring of central venous pressure (CVP). A radial artery cannula for invasive pressure measurement is usually placed. The worst femoral access is chosen for the $5 \mathrm{Fr}$ diagnostic pig tail catheter. A temporary pacing is positioned in the right ventricular (RV) apex through a venous access.

\section{Vascular accesses preparation}

Vascular accesses can be obtained in percutaneous fashion for the transfemoral, when preclosure percutaneous systems are available like Prostar XL 10 F (Abbott Vascular Devices, Redwood City, C) or with surgical exposure in all the others. There are advantages and disadvantages for both approaches. Surgical exposure is recommended for complex vascular anatomy and for transaxillary artery, increasing the procedural time and the in-hospital stay but reducing vascular complications.

The femoral artery for insertion of the 18Fr introducer (selected after reviewing CT images) is accessed under angiographic guidance. The principal points are the following:

1) A $9 F r$ introducer is inserted into the common femoral artery.

2) After confirming access, the $9 \mathrm{Fr}$ introducer is removed over a $0.035^{\prime \prime} \mathrm{J}$-wire and a 10Fr-Prostar -XL device is inserted and all four sutures are harvested in a Preclose fashion.

3) The 9Fr introducer is reinserted and a super-stiff Amplatz wire (SSA-1) is placed in the aorta.

4) An 18Fr introducer is then advanced under fluoroscopy over the SSA-1 wire above the level of the aortic bifurcation.

If surgical exposure of femoral artery is performed, after femoral artery exposure and the $9 \mathrm{~F}$ introducer insertion only the points 3 and 4 are performed. 


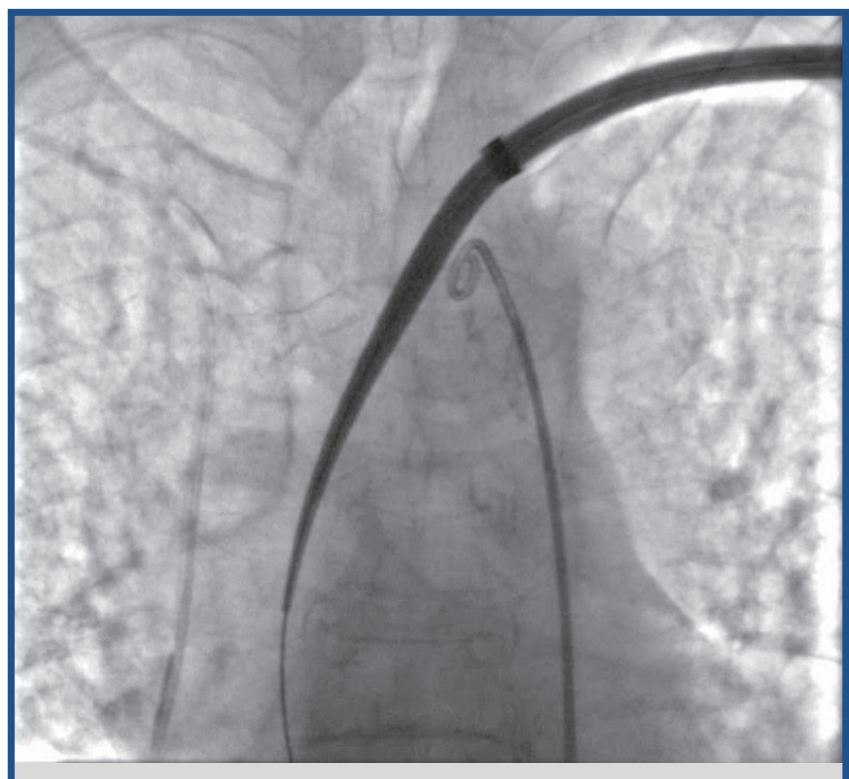

Figure 6. The $18 \mathrm{~F}$ introducer is inserted from the distal part of the left axillary artery. The tip of the introducer with radipaque marker is advanced at least 10 $\mathrm{mm}$ in the aortic arch.

When femoral access with the $18 \mathrm{Fr}$ introducer is contraindicated, the left distal axillary artery with surgical exposure can be used as alternative route ${ }^{25}$. The left arm is fixed in a position of abduction and external rotation at $90^{\circ}$ degrees. A skin and deep-tissue incision is then made along a line that follows the course of the artery originating from the apex of the axilla and projecting itself into the crook of the elbow. The axillary artery is exposed upstream and downstream to the puncture site. After isolation, the artery is accessed with a18 G needle and a 7Fr introducer is advanced over a 0.035" $145 \mathrm{~cm}$ j-tip standard guide wire. A $5 \mathrm{Fr}$ pigtail catheter is positioned in the ascending aorta above the aortic valve plane and the standard guide wire is exchanged for SSA-1 wire (Boston Scientific Corp). A small transverse nick is made in artery wall and the 18-Fr introducer is advanced till the distal radiopaque marker is protruding at least $10 \mathrm{~mm}$ in the aortic arch (figure 6). The proximal part of the introducer is secured to the skin with a 00 silk suture.

\section{Implantation technique}

After crossing the native aortic valve with a standard diagnostic Amplatz left (AL-1) catheter and straight tip wire, a SSA-1 wire with a hand shaped loop at the end is placed in the left ventricular apex in stable position using the right anterior oblique projection. A pre-implantation balloon aortc valvuloplasty is routinely performed under rapid RV pacing with an undersized balloon for preparing the native annulus except in pure aortic regurgitation or degenerated aortic bioprosthesis (figure 7).

The CoreValve implantation is performed as follow: a $5 \mathrm{fr}$ diagnostic pigtail catheter is positioned in the noncoronary cusp as a marker for the annular plane and for contrast injections during the valve release. The image

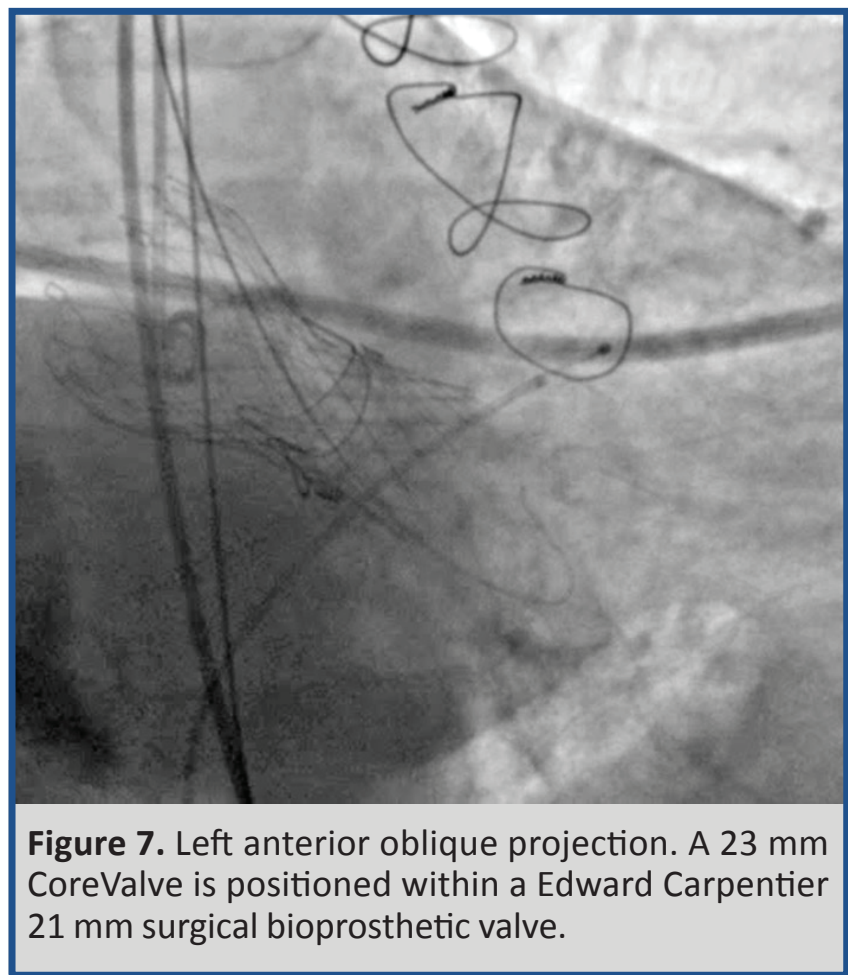

intensifier is positioned in the optimal left anterior oblique (LAO) projection for aligning all three coronary cusps in a straight line. The delivery catheter system (DCS) is positioned such that one horizontal markers of the device is positioned below the level of the pigtail catheter and the release is initiated under fluoroscopic and angiographic guidance with repeated small contrast injections (10 cc to $10 \mathrm{cc} / \mathrm{sec}$ at $900 \mathrm{psi}$ ) through the pigtail catheter. The DCS frame must be positioned 4 to $6 \mathrm{~mm}$ below the annular plane prior to initiating release of the valve frame; the release of the valve must be performed very slowly making small adjustments for compensating undesired movement; he DCS is maintained in as central a position as possible in the aortic root, After the prosthesis is released completely, the release hooks of the device are carefully observed to ensure their detachment from the DCS in LAO and right anterior oblique projection projections.

Post deployment, hemodynamic measurements and ascending aortogram must be performed to assess for presence and severity of para-prosthetic regurgitation (PPR).

\section{How to assess a paravalvular leak}

When a paravalvular leak is observed after implantation the operator should accurately evaluate the severity of the PPR, and understand the underlying mechanis . The severity of the regurgitation must be assessed using hemodynamic measurements, angiographic and echocardiographic evaluation.

The simultaneous recording of aortic pressure and left ventricular (LV) pressure gives a lot of information. When the diastolic aortic pressure is below $40 \mathrm{mmHg}$ and the LV end-diastolic pressure is higher than baseline the aortic regurgitation is likely to be severe and must be corrected (figure 8). The aortography should be performed with adequate volume and rate of contrast in- 

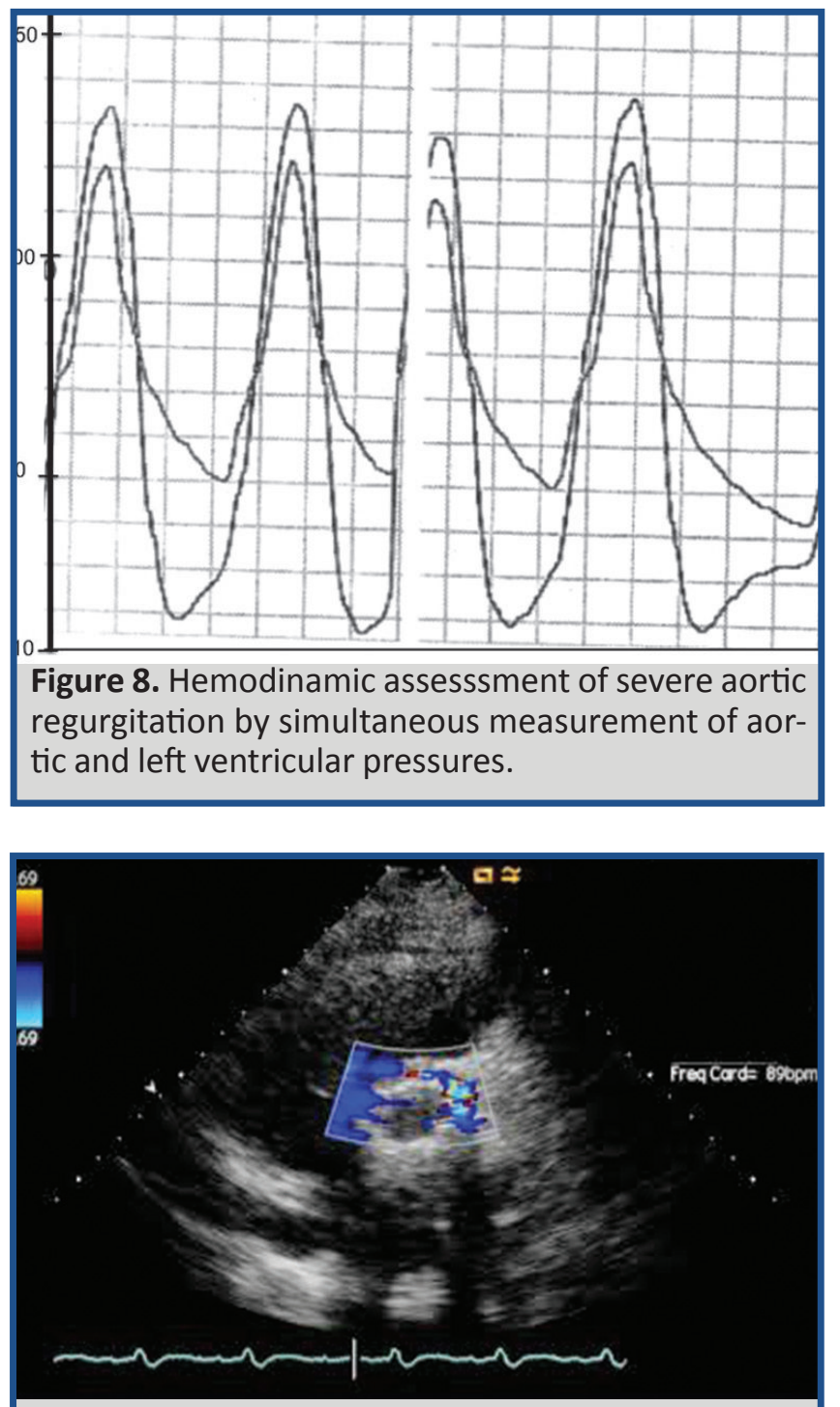

Figure 9. Transthoracic echocardiogram short axis view showing para-prosthetic leak extended from 12 to 4 o'clock.

jection in two orthogonal views in order to quantify the severity of regurgitation, identify the location and mechanism of the leak, understanding if it occurred for incomplete prosthesis expansion or incomplete apposition. In this case the inlet portion of the valve is few millimeter far away from the calcified annulus only under one cups for the presence of a calcification, or in multiple locations because undersized valve.

If there is a low valve malposition the mechanism of leak is a inadequate sealing of the inlet portion of the CoreValve, so the blood returns in the ventricle passing through the struts above the upper part of the pericardium skirt, When there is an high valve malposition we can have severe regurgitation and /or coronary ostia obstruction by the inlet part of the prosthesis.

The trans-thoracic echocardiography is a useful diagnostic tool, when the acoustic window is optimal, and using the three main views (parasternal long axis, parasternal short axis and the apical five chamber), it is possible to understand the position and extension of the leak, the severity of regurgitation and the impairment of the LV (figure 9).
If there is a under expansion of the valve, or malapposition of one side of the valve, balloon post dilatation is recommended during a careful right ventricular pacing for reducing the left ventricular systolic pressure in order to obtain a stable balloon position. If the valve is too high, the first maneuver is to snare the valve from one of the two hooks and pull the valve in the ascending aorta, because the danger of coronary flow obstruction. Then place a second valve. The so called „valve- on-valve”, does not impair the device function. If the valve is too low try to pull the valve of few mm using a snare with a „pull and stop" technique: the snare is inserted from one of the femoral artery, and one of the two hooks is catched and start pulling till when the beating heart is felt the stop and maintain the position, wait few minutes and then start again $^{26}$. Sometimes the femoral approach is not uncomfortable for snaring the valve, in this case from an artery access from the left arm (radial or brachial) for obtaining a better catheter snare direction of traction ${ }^{27}$. If this maneuver is ineffective, the "valve-in-valve" technique is the second option, placing a second valve within the first ${ }^{28,29}$.

Once the prosthesis is successfully deployed, removal of vascular catheters is carried out in the catheterization laboratory. The temporary pacemaker electrode placed into the right ventricle through a femoral vein is maintained for 24-48 hours.

\section{Post procedural Intensive care management}

The post-operative care is challenging because of the incidence of procedural and post procedural life threatening complications related to the invasiveness of TAVI and to the abrupt hemodynamic changes occurring after the sudden relief of valvular obstruction in patients with a chronically low cardiac output state ${ }^{30}$.

After the procedure all patients are routinely transferred to the ICU. During the first 48 hours, vital parameters are continuously monitored by a nurse. Close attention has to be given to rhythm and atrio-ventricular conduction disturbances, systemic blood pressure and fluid balance, monitoring diuresis and adjusting intravenous fluid administration in order to maintain CVP between 5 to $10 \mathrm{mmHg}$. Oxygen saturation values are obtained from transcutaneous pulse oximetry, with arterial blood gas test when necessary

Assessment of cardiologic symptoms, such as palpitations, chest pain, fatigue and shortness of breath, and examination of mental status, including consciousness, orientation and memory, require a careful observation of patients for the early detection of signs of acute heart failure or neurological deficit.

Vascular accesses and peripheral pulses are monitored for hematoma, pseudo-aneurysm or acute thrombosis. When necessary a peripheral echo-Doppler is performed.

To prevent infections, stringent cleaning of vascular accesses and care of urinary catheter are daily advised. If signs of systemic infection are present, blood and/or urinary cultures are ordered.

Laboratory tests are performed daily and consisted in: blood routine count for detecting signs of occult 
bleeding, infection, dual antiplatelet therapy intolerance or heparin induced thrombocytopenia and for the assessment of renal function to diagnose acute kidney insufficiency (AKI) defined as a decrease of $>25 \%$ in eGFR at 48 hours following the procedure or the need of haemodialysis during hospitalization [31-35]. The degree of AKI is further classified as: (i) mild (>25\% decrease in eGFR); (ii) moderate (50-75\% decrease in eGFR), and (iii) severe (>75\% decrease in eGFR).(36)

Other routine laboratory test included: electrolytes serum concentrations, liver and muscular enzymes and clotting parameters.

A trans-thoracic echocardiogram is planned 6 hours after TAVI and then every 24 hours, to assess optimal position of the prosthesis, trans-prosthetic gradient, paravalvular leak or aortic regurgitation, mitral valve and left ventricular function, systolic pulmonary arterial pressure and pericardial effusion.

Standard medical therapy include low molecular weight heparin until ambulation, appropriate antibiotic therapy for three days, acetylsalicylic acid $(100 \mathrm{mg})$ and Clopidogrel (75mg) daily; inotropic support, antihypertensive and diuretic therapy if needed.

Early patient ambulation, within $24 / 48$ hours, is encouraged to prevent complications, such as muscle atrophy, constipation, decubitus ulcers, thrombo-phlebitis and to reduce length of hospital-stay. Patients should undergo physical rehabilitation just after mobilization and pulmonary rehabilitation in patients with pulmonary diseases expecially in case of intra-procedural endo-tracheal intubation.

Renal failure. Chronic kidney disease is a predisposing factor for post-procedural AKI (30-35). However, patients with normal baseline renal function can develop post-procedural AKI despite a low volume of contrast medium used. These patients can have an intense polyuric phase soon after TAVI, followed by an oliguric status. The mechanism can be the sudden decrease in heart filling pressures matched to a significant increase in cardiac output and kidney perfusion just after valve implantation. This polyuria is followed by intravascular volume reduction, confirmed by a marked drop in CVP, which led to a prerenal acute renal failure. Therefore, a careful monitoring of the fluid balance with continuous CVP measurement and intravenous volume repletion to correct fluid loss is mandatory to lower the rate of AKI. When pre-renal acute renal failure occurs protocol for fluid replacement therapy tailored to maintain the CVP value between 5 to $10 \mathrm{mmHg}$.

Diuretics have to be administered only in those patients with low left ventricular ejection fraction, severe LV diastolic dysfunction, coexistence of severe mitral regurgitation and RV dysfunction with severe pulmonary hypertension; also patients with persistent oliguria despite optimization of intravascular volumes and cardiopulmonary hemodynamics could benefit from diuretic drugs.

Vascular complications. Femoral artery pseudoaneurism (FAP) is the most common vascular complication after TAVI. Physical examination of vascular accesses sites and peripheral pulses have to be systematically performed every 3 hours looking for bleeding, pulsatile hematoma or acute signs of limb ischemia. Color Doppler ultrasound scanning can be performed in cases of groin pulsatile masses to confirm or to exclude the presence of FAP. Manual compression repair under ultrasound monitoring significantly reduce the need for surgical repair of FAP, leading to early patient ambulation and short hospital stay. Surgical vascular intervention is the preferred as first-line treatment in patients with signs of acute haemodynamic compromission or if manual compression failed $(30,37)$.

Conduction Disturbances. These frequently consist in Left Bundle Branch Block (LBBB), or advanced or complete atrio-ventricular block (AVB) within the first 24 hours of TAVI. Complete AVB is a potential acute and late complication of TAVI. It is hypothesized that continued prosthesis expansion can cause a mechanical trauma to the conduction system, particularly in patients with calcified aortic annulus, worsening pre-existing conduction defects or generating new ones. The atrioventricular node is in fact in close proximity to the subaortic region and membranous septum of left ventricle outflow tract. Therefore proper positioning of the prosthesis within the left ventricular outflow tract may limit risk of conduction abnormalities and potentially the need for pacing [39]. It is now recommended to position the proximal end of the valve frame $<6 \mathrm{~mm}$ from the lower edge of the noncoronary cusp. Permanent pacemaker implantation is recommended as early as possible.

Cerebrovascular accident is a rare complication, ranging from 2 to $4 \%(7-12,40,41)$, they occur intraprocedurally, and mostly are minor stroke. Severe aortic arch calcificationscan be a source of increased embolization during wire manipulation, catheter exchanges in aorta and when the device is retrieved and then repositioned. In this case the flared distal part of the prosthesis can scratched the atheromatous aortic wall resulting in cerebral micro-embolization.

Thrombocytopaenia usually is caused by anticoagulant therapy, as confirmed by the rapid and spontaneous resolution after heparin withdrawal (42). The use of fondaparinux as thromboembolic prophylaxis is attractive and we recently introduced in postoperative protocol as routine anticoagulation. All these data emphasize the importance of a strict platelet count control.

Currently, the optimal antithrombotic prophylaxis remains embroiled in controversies $(43,44)$. About Corevalve prosthesis, it is only speculated that before the process of endothelization, the risk of thrombosis induced by the prosthesis is high and that dual antiplateled therapy should be advocated for at least the first three months after the implantation. However, taking into account that there are no reports on embolic events after TAVI, the perceived high risk of developing valve thrombosis and systemic thromboembolism may not be real. Our experience shows that the use of dual antiplatelet therapy is to some extent "empirical" and that in selected patients, without unstable coronary artery disease, the long-life use of aspirin is effective, more economic and possibly better tolerated by pa- 
tients. After TAVI dual antiplatelet therapy with aspirin and clopidogrel for three up to six months is currently recommended, but there is no scientific evidence supporting this strategy (43). Therefore antithrombotic therapy with aspirin alone can be offered in those patients at high risk of major bleeding

\section{Conclusions}

TAVI is a novel technique for the interventional cardiologist, which requires a careful assessment of the clinical conditions of candidate patients in order to have a safe and effective procedure. The post-operative care needs a level of attention higher than other percutaneous interventions, due to the high-risk characteristics of this patient population such as advanced in age, frailty and comorbidities. The potential complications are known, but a standardized monitoring and management protocol and a specific training of caregivers would be useful for the early recognition and treatment of complications, which will result in a more favourable outcome.

\section{References}

1. Zajarias A, Cribier AG. Outcomes and safety of percutaneous aortic valve replacement. J Am Coll Cardiol 2009;53:1829-1836.

2. Rodés-Cabau J, Webb JG, Cheung A, Ye J, Dumont E, Feindel CM, Osten M, Natarajan MK, Velianou JL, Martucci G, Devarennes B, Chisholm R, Peterson MD, Lichtenstein SV, Nietlispach F, Doyle $D$, Delarochellière R, Teoh K, Chu V, Dancea A, Lachapelle K, Cheema A, Latter D, Horlick E. Transcatheter Aortic Valve Implantation for the Treatment of Severe Symptomatic Aortic Stenosis in Patients at Very High or Prohibitive Surgical Risk Acute and Late Outcomes of the Multicenter Canadian Experience. J Am Coll Cardiol 2010.

3. Piazza N, Grube E, Gerckens U, Den Heijer P, Linke A Luha O, Ramondo A.B., Ussia GP, Wenaweser P, Windecker S, Laborde J.C.,De Jaegere P, Serruys P.W: on the behalf of the clinical centres who actively participated in the registry. Procedural and 30-day outcomes following transcatheter aortic valve implantation using the third generation (18 Fr) CoreValve ReValving System: results from the multicentre, expanded \evaluation registry 1-year following CE mark approval. Eurolnterv 2008; 4: 242-249.

4. Leon MB, Smith CR, Mack M, Miller DC, Moses JW, et al. Transcatheter aortic-valve implantation for aortic stenosis in patients who cannot undergo surgery. N Engl J Med 2010;363:1597-1607.

5. Authors/Task Force Members, Vahanian A, Alfieri O, et al. Guidelines on the management of valvular heart disease (version 2012): The Joint Task Force on the Management of Valvular Heart Disease of the European Society of Cardiology (ESC) and the European Association for Cardio-Thoracic Surgery (EACTS). European Heart Journal 2012;33:2451-2496.

6. Vahanian A, Alfieri O, Al-Attar N, Antunes M, Bax J, Cormier B, Cribier A, De Jaegere P, Fournial G, Kappetein AP, Kovac J, Ludgate $S$, Maisano F, Moat N, Mohr F, Nataf P, Pièrard L, Pomar JL, Schofer J, Tornos P, Tuzcu M, van Hout B, Von Segesser LK, Walther T, Transcatheter valve implantation for patients with aortic stenosis: a position statement from the European Association of Cardio-Thoracic Surgery (EACTS) and the European Society of Cardiology (ESC), in collaboration with the European Association of Percutaneous Cardiovascular Interventions (EAPCI). Eur Heart J 2008; 11: 1463-1470.

7. Tamburino C, Capodanno D, Mulè M, Scarabelli M, Cammalleri V, Barbanti M, Calafiore A, Ussia GP. Procedural success and 30day clinical outcomes after percutaneous aortic valve replacement using current third-generation self-expanding CoreValve prosthesis.J Invasive Cardiol 2009 Mar;21(3):93-98.

8. Ussia GP, Barbanti M, Petronio AS, Tarantini G, Ettori F, Colombo A, Violini R, Ramondo A, Santoro G, Klugmann S, Bedogni F, Mai- sano F, Marzocchi A, Poli A, De Carlo M, Napodano M, Fiorina C, De Marco F, Antoniucci D, de Cillis E, Capodanno D, Tamburino C; CoreValve Italian Registry Investigators Transcatheter aortic valve implantation: 3-year outcomes of self-expanding CoreValve prosthesis. Eur Heart J 2012;33:969-76.

9. Zahn R, Gerckens U, Linke A, Sievert H, Kahlert P, Hambrecht R, Sack S, Abdel-Wahab M, Hoffmann E, Schiele R, Schneider S, Senges J; German Transcatheter Aortic Valve Interventions-Registry Investigators. Predictors of one-year mortality after transcatheter aortic valve implantation for severe symptomatic aortic stenosis. Am J Cardiol 2013;112:272-9.

10. Moat NE, Ludman $P$, de Belder MA, Bridgewater $B$, Cunningham $A D$, Young $C P$, Thomas M, Kovac J, Spyt T, MacCarthy PA, Wendler O, Hildick-Smith D, Davies SW, Trivedi U, Blackman DJ, Levy RD, Brecker SJ, Baumbach A, Daniel T, Gray H, Mullen MJ. Long-term outcomes after transcatheter aortic valve implantation in highrisk patients with severe aortic stenosis: the U.K. TAVI (United Kingdom Transcatheter Aortic Valve Implantation) Registry. J Am Coll Cardiol 2011;58:2130-8.

11. Gilard M1, Eltchaninoff $H$, lung $B$, Donzeau-Gouge $P$, Chevreul $K$, Fajadet J, Leprince $P$, Leguerrier A, Lievre M, Prat A, Teiger E, Lefevre T, Himbert D, Tchetche D, Carrié D, Albat B, Cribier A, Rioufol G, Sudre A, Blanchard D, Collet F, Dos Santos P, Meneveau $\mathrm{N}$, Tirouvanziam A, Caussin C, Guyon P, Boschat J, Le Breton $\mathrm{H}$, Collart F, Houel R, Delpine S, Souteyrand G, Favereau X, Ohlmann P, Doisy V, Grollier G, Gommeaux A, Claudel JP, Bourlon F, Bertrand B, Van Belle E, Laskar M; FRANCE 2 Investigators. Registry of transcatheter aortic-valve implantation in high-risk patients. N Engl J Med 2012;366:1705-15.

12. Toggweiler S, Humphries KH, Lee M, Binder RK, Moss RR, Freeman M, Ye J, Cheung A, Wood DA, Webb JG. 5-year outcome after transcatheter aortic valve implantation. J Am Coll Cardiol. 2013 Jan 29;61(4):413-9.

13. Kodali SK, Williams MR, Smith CR, Svensson LG, Webb JG, Makkar RR, Fontana GP, Dewey TM, Thourani VH, Pichard AD, Fischbein M, Szeto WY, Lim S, Greason KL, Teirstein PS, Malaisrie SC, Douglas PS, Hahn RT, Whisenant B, Zajarias A, Wang D, Akin JJ, Anderson WN, Leon MB; PARTNER Trial Investigators. Two-year outcomes after transcatheter or surgical aortic-valve replacement. N Engl J Med 2012;366:1686-95.

14. Roques F, Nashef SA, Michel P, Gauducheau E, de Vincentiis C,Baudet E, Cortina J, David M, Faichney A, Gabrielle F, Gams E, Harjula A, Jones MT, Pintor PP, Salamon R, Thulin L. Risk factors and outcome in European cardiac surgery: analysis of the EuroSCORE multinational database of 19030 patients. Eur J Cardiothorac Surg 1999;15:816-822.

15. . Nashef SAM, Roques F, Sharples LD, et al. EuroSCORE II. Eur J Cardiothorac Surg 2012;41:734-745.

16. Dewey T. M, Brown D, Ryan W.H, Herbert M.A, Prince S. L, and Mack M. J, Reliability of risk algorithms in predicting early and late operative outcomes in high-risk patients undergoing aortic valve replacement. J Thorac Cardiovasc Surg 2008;135:180-7

17. Wendt D, Osswald B. R, Kayser K, Thielmann M, Tossios P, Massoudy $\mathrm{P}$, Kamler M, and Jakob H. Society of Thoracic Surgeons Score Is Superior to the EuroSCORE Determining Mortality in High Risk Patients Undergoing Isolated Aortic Valve Replacement. Ann Thorac Surg 2009;88:468-75.

18. Vassiliades TA Jr, Block PC, Cohn LH, Adams DH, Borer JS, Feldman T, Holmes DR, Laskey WK, Lytle BW, Mack MJ, Williams DO; Society of Thoracic Surgeons (STS); American Association for Thoracic Surgery (AATS); Society for Cardiovascular Angiography and Interventions (SCAI); American College of Cardiology Foundation (ACCF); American Heart Association (AHA). The clinical development of percutaneous heart valve technology: a position statement of the Society of Thoracic Surgeons (STS), the American Association for Thoracic Surgery (AATS) and the Society for Cardiovascular Angiography and Interventions (SCAI). Ann Thorac Surg 2005; 79:1812-1818.

19. Kappetein AP, Head SJ, Généreux P, Piazza N, van Mieghem NM, Blackstone EH, Brott TG, Cohen DJ, Cutlip DE, van Es GA, Hahn RT, Kirtane AJ, Krucoff MW, Kodali S, Mack MJ, Mehran R, Rodés-Cabau J, Vranckx P, Webb JG, Windecker S, Serruys PW, Leon MB. Updated standardized endpoint definitions for transcatheter aor- 
tic valve implantation: the Valve Academic Research Consortium-2 consensus document (VARC-2). Eur Heart J 2012;33:2403-18.

20. Buellesfeld L, Stortecky S, Kalesan B, et al. Aortic root dimensions among patients with severe aortic stenosis undergoing transcatheter aortic valve replacement. JACC Cardiovasc Interv 2013;6:72-83.

21. Walther T, Simon P, Dewey T, et al. Transapical minimally invasive aortic valve implantation: multicenter experience. Circulation 2007; 116:1240.

22. Petronio AS, De Carlo M, Bedogni F, Marzocchi A, Klugmann S, et al. Safety and efficacy of the subclavian approach for transcatheter aortic valve implantation with the CoreValve revalving system. Circulation Cardiovasc Interv 2010;3:359-366.

23. Modine T, Sudre A, Collet F, Delhaye C, Lemesles G, Fayad G, Koussa M. Transcutaneous aortic valve implantation using the axillary/subclavian access with patent left internal thoracic artery to left anterior descending artery: feasibility and early clinical outcomes. J Thorac Cardiovasc Surg 2012;144:1416-20.

24. Latsios G, Gerckens U, Grube E. Transaortic transcatheter aortic valve implantation: a novel approach for the truly no-access option patients. Catheter Cardiovasc Interv 2010;75:1129-1136.

25. Ussia GP, Cammalleri V, Ascoli Marchetti A, Sarkar K, De Vico P, Muscoli S, Sergi D, Marchei M, Ippoliti A, Romeo F. Transcatheter aortic valve implantation through distal axillary artery: novel option for vascular access. J Cardiovasc Med (Hagerstown) 2014. Doi: 10.2459/JCM.0000000000000063

26. Ussia G., Barbanti M, Sarkar K, Aruta P, Scarabelli M, Cammaller V, Imme S, Pistritto Am, Gulino S, Mule M, Deste W, Cannata S, Tamburino C (2012). Transcatheter Aortic Bioprosthesis Dislocation: Technical Aspects And Midterm Follow-Up. Eurointervention, Vol. 7; P. 1285-1292.

27. Ussia GP, Barbanti M, Immè S, Scarabelli $M$, Mulè M, Cammalleri V, Aruta P, Pistritto AM, Capodanno D, Deste W, Di Pasqua MC, Tamburino C. Management of implant failure during transcatheter aortic valve implantation. Catheter Cardiovasc Interv. 2010;76:440-9.

28. Ussia GP, Barbanti M, Ramondo A, Petronio AS, Ettori F, Santoro G, Klugmann S, Bedogni F, Maisano F, Marzocchi A, Poli A, Napodano $M$, Tamburino $C$. The valve-in-valve technique for treatment of aortic bioprosthesis malposition an analysis of incidence and 1-year clinical outcomes from the italian CoreValve registry. J Am Coll Cardiol 2011;57:1062-8.

29. Ussia GP, Mulè M, Tamburino $C$. The valve-in-valve technique: transcatheter treatment of aortic bioprothesis malposition. Catheter Cardiovasc Interv 2009;73:713-6.

30. Ussia G., Scarabelli M, Mule M, Barbanti M, Cammalleri V, Imme $S$, Aruta P, Pistritto Am, Carbonaro A, Deste W, Sciuto P, Lic ciardello G, Calvi V, Tamburino C. Postprocedural Management Of Patients After Transcatheter Aortic Valve Implantation Proicedure With Self Expanding Bioprostehsis. Catheter Cardiovasc Interv. 2010 Nov 1;76(5):757-66.

31. Tepel M, van der Giet M, Schwarzfeld C, Laufer U, Liermann D, Zidek W. Prevention of radiographic-contrast-agent-induced reductions in renal function by acetylcysteine. N Engl J Med 2000 Jul 20;343(3):180-184.
32. Birck R, Kzossok S, Markowetz F, Schnulle P, Van der Woude FJ, Braun C. Acetylcysteine for prevention of contrast nephropathy: meta-analysis. Lancet 2003; 362: 598-603.

33. Mueller C, Buerkle G, Buettner HJ, Petersen J, Perruchoud AP, Eriksson U, Marsch S, RoSkamm H. Prevention of contrast mediaassociated nephropathy; randomized comparison of 2 hydration regimens in 1620 patients undergoing coronary angioplasty. Arch Intern Med 2002; 162: 329-336.

34. Briguori C, Colombo A, Violante A, Balestrieri P, Manganelli F, Elia PP, Golia B, Lepore S, Riviezzo G, Scarpato P, Focaccio A, Librera $\mathrm{M}$, Bonizzoni E, Ricciardelli B. Standard vs double dose of $\mathrm{N}$ acetylcysteine to prevent contrast agent associated nephrotoxicity. European Heart Journal (2004) 25, 206-211.

35. Bagur R, Webb JG, Nietlispach F, Dumont E, De Larochelliere R, Doyle D, Masson JB, Gutierrez MJ, Clavel MA, Bertrand OF, Pibarot $P$, Rodes- Cabau J. Acute kidney injury following transcatheter aortic valve implantation: predictive factors, prognostic value, and comparison with surgical aortic valve replacement. Eur Heart J 2009.

36. Bellomo R, Kellum JA, Ronco C. Defining and classifying acute renal failure: from advocacy to consensus and validation of the RIFLE criteria. Intensive Care Med 2007; 33:409-413.

37. Fellmeth BD, Roberts AC, Bookstein JJ, et al. Postangiographic femoral artery injuries: nonsurgical repair with US-guided compression. Radiology 1991; 178:671-675.

38. Fraccaro C, Napodano M, Tarantini G, Gasparetto V, Gerosa G, Bianco R, Bonato R, Pittarello D, Isabella $G$, lliceto $S$ and Ramondo A. Expanding the Eligibility for Transcatheter Aortic Valve Implantation: The Trans-Subclavian Retrograde Approach Using the III Generation CoreValve Revalving System. J Am Coll Cardiol Intv 2009;2:828-833.

39. Piazza N, Onuma Y, Jesserun E, Kint PP, Maugenest AM, Anderson RH, de Jaegere PP, Serruys PW. Early and persistent intraventricular conduction abnormalities and requirements for pacemaking after percutaneous replacement of the aortic valve. JACC Cardiovasc Interv 2008;1:310-316.

40. Hynes BG, Rodés-Cabau J. Transcatheter aortic valve implantation and cerebrovascular events: the current state of the art. Ann N Y Acad Sci 2012 Apr;1254:151-63.

41. Tay EL1, Gurvitch R, Wijesinghe N, Nietlispach F, Wood D, Cheung A, Ye J, Lichtenstein SV, Carere R, Thompson C, Webb JG. A high-risk period for cerebrovascular events exists after transcatheter aortic valve implantation. JACC Cardiovasc Interv 2011:4:1290-7.

42. Shantsila E, Lip GYH and Chong BH. Heparin-Induced Thrombocytopenia Chest 2009;135;1651-1664.

43. Ussia G., Scarabelli M, Mule M, Barbanti M, Sarkar K, Cammalleri $\mathrm{V}$, Imme S, Aruta P, Pistritto Am, Gulino S, Deste W, Capodanno D, Tamburino C (2011). Dual Antiplatelet Therapy Versus Aspirin Alone In Patients Undergoing Transcatheter Aortic Valve Implantation. Am J Cardiol 2012;108:1772-1776.

44. Lynch DR Jr, Dantzler D, Robbins M, Zhao D. Considerations in antithrombotic therapy among patients undergoing transcatheter aortic valve implantation. J Thromb Thrombolysis. 2013 May;35(4):476-82. 